Orbis Tertius, vol. XXII, $n^{\circ}$ 26, e058, diciembre 2017. ISSN 1851-7811

Universidad Nacional de La Plata

Facultad de Humanidades y Ciencias de la Educación

Centro de Estudios de Teoría y Crítica Literaria

\title{
Qué es, qué fue y cuál es el futuro de la lectura
}

\author{
Juan Poblete * \\ * University of California-Santa Cruz, Estados Unidos
}

Las tres preguntas deben ser respondidas en al menos tres dimensiones: primero, ¿Qué es la lectura como tal, en cuanto actividad que involucra las funciones cognitivas y el cuerpo? En segundo lugar, ¿qué ha sido la lectura históricamente?, ¿cómo ha evolucionado, cómo ha sido usada, por quién, con qué efectos y en qué contextos? Finalmente, ¿cuál podría ser su condición actual y su futuro? Responder estas preguntas sólo al primer nivel sería pensar que, en cuanto práctica, la lectura ha sido siempre la misma, con la misma función en la vida cognitiva y emocional de los lectores, y sin variaciones históricas en sus usos por múltiples actores (entre ellos gobiernos nacionales, iglesias, movimientos sociales, etc.) en numerosos contextos geoculturales e institucionales (Poblete 2004a). Responder las preguntas sólo al segundo nivel, por otro lado, ha significado con frecuencia dar por descontado cuál era la naturaleza de la práctica de lectura involucrada. Hoy en día ello significaría ignorar los avances en los campos de estudios tecnológicos, de cognición y de neurociencia y lo que dichos estudios nos señalan acerca de las consecuencias de la lectura al nivel cerebral y en cuanto práctica que supone diferentes interfaces entre las tecnologías y los seres humanos. La respuesta a la tercera dimensión involucrará distinguir entre lectura profunda (deep reading) e hiperlectura (hyper reading) en tanto prácticas específicas de atención a ciertos materiales escritos en diferentes medios. Estas formas de lectura, a su vez, han sido desarrolladas históricamente en conexión con prácticas sociales e instituciones específicas. Una respuesta adecuada sobre su futuro en la educación literaria debe reconocer estas genealogías si quiere ser productiva y no simplemente reactiva.

\section{¿Qué es la lectura?}

Dos libros relativamente recientes proporcionan una excelente guía para responder la pregunta acerca de qué es la lectura en cuanto tal, como actividad que involucra las funciones cognitivas y el cuerpo. Los libros son Proust and the Squid. The Story and Science of the Reading Brain (2007) de Maryanne Wolf y Theories of Reading: Books, Bodies, and Bibliomania (2006) de Karin Littau.

Proust and the Squid. The Story and Science of the Reading Brain (2007) permite avanzar significativamente en el esfuerzo por conceptualizar la lectura como proceso cognitivo con importantes consecuencias (neurológicas, cognitivas, e informacionales) tanto al nivel individual como al social.

Cita sugerida: Poblete, J. (2017). Qué es, qué fue y cuál es el futuro de la lectura. Orbis Tertius, $22(26)$, e058. https://doi.org/10.24215/18517811e058 
Para Wolf la lectura se define por su capacidad generativa para ir más allá de lo dado. Para ello la lectura reproduce y depende de la plasticidad del cerebro, es decir, de su arquitectura abierta y de su capacidad para transformar su circuito (circuit wiring) e “ir más allá del diseño original de sus estructuras” (2007: 15). Neurológicamente, pero también históricamente, la lectura ha permitido a la especie humana reordenar "la organización misma de nuestro cerebro, lo que a su vez expandió las maneras en que pensamos [sobre nosotros y los otros, sobre nosotros en relación con nosotros mismos y con los otros] Esto último, por otro lado, alteró la evolución intelectual de nuestra especie” (2007: 3).

Esta capacidad para ir más allá de lo dado depende de lo que Stanislas Dehaene ha llamado "reciclaje neuronal” y fisiológicamente involucra lo que Wolf denomina los tres principios de la arquitectura cerebral que la lectura explota: "la capacidad para establecer nuevas conexiones entre estructuras ya existentes, la capacidad de constituir áreas de una exquisita y precisa especialización para reconocer patrones en la información; y la capacidad de aprender a usar y conectar información de esas áreas de manera automática” (2007: 12).

De este modo, Wolf puede describir la lectura como la cabal integración de una serie de procesos: una conducta (el acto físico de leer una palabra en un libro) y un proceso cognitivo que a su vez consiste en procesos “atencionales, perceptuales, conceptuales, lingüísticos, y motores” (2007: 10). A diferencia de lo visual y de la palabra que son genéticamente pre-programados, la lectura debe crear sus propias vías o conexiones neurológicas entre los procesos visuales, conceptuales y lingüísticos involucrados. Es decir que la estructura específica del cerebro lector se adquiere, no se hereda. En ello radica la dificultad de aprender a leer, pero también sus beneficios para el individuo y su cerebro. Para hacer posible esta capacidad generativa con cada acto de lectura, el cerebro economiza energía y tiempo. Lo hace por la vía de automatizar el circuito neuronal así creado, generando representaciones de letras, palabras y conceptos fácilmente usables e inmediatamente disponibles. Una vez que el cerebro reconoce con éxito los inputs visuales (o aurales), semánticos, sintácticos e informacionales, el cerebro lector produce todo tipo de inferencias y conexiones nuevas o ya entrenadas. Al explotar esta creciente efectividad, el cerebro lector hace posible mejores y más pensamientos nuevos para más gente y a una más temprana edad.

En este proceso el lector o la lectora pasa a través de cinco etapas claramente reconocibles: "(1) el pre-lector emergente, (2) el lector novicio, (3) el lector decodificador, (4) el lector con fluidez y comprensión, y (5) el lector experto" (Wolf 2007: 114-115). De la primera a la última de estas etapas una de las cosas más importantes que gana la lectora es tiempo. El procesamiento optimizado y automatizado de signos y conceptos, las formas repetidamente practicadas de atención, decodificación e inferencia, permiten más tiempo para pensar cosas nuevas, para ir más allá del texto. Este tiempo extra pueden ser los milisegundos que permiten establecer la secuencia correcta entre percepción, memoria y comprensión, que son la mecánica de la lectura, o bien puede ser la pausa más larga que hace posible la reflexión y una percepción cambiada del contenido, del yo y de los otros, elementos que definen el sentido más profundo de la práctica de lectura. La conclusión de Wolf es que "Un sistema que puede optimizarse por la vía de la especialización y la automatización tiene más tiempo para pensar" (2007: 216) y nos afecta no sólo cuando leemos sino, más generalmente, cuando pensamos: "El diseño del cerebro hizo posible la lectura, y el diseño de la lectura cambió el cerebro de la especie de maneras múltiples, críticas y aun en evolución” (2007: 216).

El libro de Maryanne Wolf nos permite, entonces, comprender qué es la lectura y cuál ha sido su impacto en este nivel neurológico, cognitivo y civilizacional general. La lectura y el libro han sido tecnologías claves para la producción, amplificación, almacenamiento, uso y transmisión de la memoria humana. Han sido también instrumentos radicales en la transformación y fructífero cultivo de la capacidad de nuestro cerebro para producir algo nuevo, para ir más allá de las limitaciones de lo dado. Aunque en la modernidad la lectura ha sido también una herramienta para la socialización y el desarrollo moral en la educación de los niños, la historia que más le interesa a Wolf destaca a la lectura como una herramienta clave para el desarrollo cognitivo e intelectual de la especie. 
Este énfasis de Wolf muestra una consecuencia bien material y clave de la lectura que afecta las funciones cognitivas de nuestro cerebro y nuestra capacidad para procesar, analizar y aprender de nuestras experiencias de lectura. Pero ¿qué ocurre, podríamos preguntar, con las consecuencias de la lectura en relación al resto de nuestros cuerpos y nosotros mismos? Si ahora tomamos, no la historia del desarrollo del niño o del cerebro, sino la historia de la lectura misma, ¿qué es lo que podríamos agregar a esta visión del impacto civilizacional de la lectura? Un libro excepcional de Karin Littau, Theories of Reading: Books, Bodies and Bibliomania nos ayudará a aclarar algunas respuestas y a entender mejor qué está en juego en la formulación de las preguntas mismas.

Littau parte de dos premisas metodológicas: primero, que la teoría literaria moderna, incluso la teoría de la recepción u orientada a los lectores, ha tenido un prejuicio o una inclinación mentalista y, a la hora de considerar la relación entre lo literario y su lector, ha privilegiado sistemáticamente el hacer o tener sentido (sense making) sobre el sentimiento, la interpretación sobre la sensación. Yendo en la dirección contraria, y siguiendo las tempranas indicaciones de Jane Tompkins, Littau prefiere destacar una historia de la lectura literaria que de cuenta del cuerpo y sus afectos, y que conciba a la literatura menos como una ocasión para la interpretación y más como una ocasión para el sentir. La segunda premisa metodológica de Littau deriva de la primera: el estudio de la literatura y de la lectura pertenece no sólo al campo de las humanidades históricas, con su tradición centrada en el texto, sino también al de la historia de los medios y sus efectos, y más precisamente allí, al punto donde la historia de los medios se encuentra con la historia material y de las tecnologías.

Para Littau "el grueso de las teorías orientadas al lector en el siglo veinte (...) se ocupan predominantemente de cómo los lectores construyen el sentido de un texto (Culler, Fish, Iser, Jauss, Gadamer); cómo los textos frustran los intentos de los lectores de construir dicho sentido (de Man, Miller, Bloom, Derrida); o de cómo los lectores resisten los sentidos de ciertos textos (Fetterley, Radway, Bobo)” (2006: 10). Lo que se olvida sistemáticamente, incluso en estas teorías históricamente orientadas, es “el cuerpo del lector o la lectora” (2006: 11).

Recuperar el cuerpo y sus afectos para una historia de la lectura le permite a Littau el rescate de una comprensión históricamente diversa de lo que la literatura es y ha sido. Aquí “ la estética Kantiana del desinterés racional” y la contemplación formal se enfrenta a una tradición alternativa que se remonta al menos hasta la retórica griega clásica y alcanza hasta "la estética como psicología" (2006: 6) de Nietzsche y el hipertexto. Si lo que Kant proponía era una relación con el arte basada en una "apatheia cognitiva y no en el pathos”, la tradición retórica griega le enseña al poeta "cómo incitar tales pasiones”, mientras que Nietzsche “celebra el rapto” y "el peligro fisiológico del arte” (2006: 8).

La bibliomanía — es decir la condena que hacen el siglo XVIII y XIX de la lectura de novelas debido a su asociación con y denuncia como enfermedad, como un hambre incontrolable de sensaciones - le abre a Littau la posibilidad de formular su tesis principal: “ la bibliomanía es parte de un malestar cultural más amplio, específicamente asociado a la modernidad: la sobreestimulación sensorial” (2006: 5). En ese sentido la bibliomanía es parte de un continuo en la historia de la atención en la cual "lo fisiológico, lo material y lo tecnológico” (2006:3) se entrelazan. En dicha historia, en la cual lo estético se encuentra con el mercado y con nuevas tecnologías, hay tres tecnologías que le interesan a Littau por su capacidad de determinar nuestra relación con la palabra escrita y explotar las formas de nuestra atención: la imprenta, el cine, y la internet. Lo que tienen en común es que son capaces de alterar "no sólo nuestra relación con la lectura y la escritura sino nuestra percepción del mundo y tal vez incluso (...) la percepción misma” (2006:3). Con frecuencia se temió y se teme que las consecuencias de la bibliomanía extrema sean "la negación de la autonomía del sujeto, y con ella, la idea humanista de la agencia racional” (2006:5). Yendo en contra de tales antiguas y contemporáneas denuncias, y siguiendo la tradición de Benjamin, Simmel y Kracauer, Littau propone una conexión entre lo que llama las condiciones "socio-fisiológicas" de la modernidad y la vida urbana y las formas de percepción y experiencia estimuladas por la lectura de novelas, el cine y el hipertexto. En este contexto, los conceptos principales que emergen para el estudio de la lectura son la distracción, la estimulación múltiple y el completo involucramiento del cuerpo (por oposición a simplemente la cognición o la interpretación.) Esas tres tecnologías tienen, entonces, 
la capacidad y el efecto histórico de alterar nuestra percepción sensorial del mundo. Littau concluye:

[...] puesto que ninguna cultura humana es posible sin una fisiología y una tecnología que la hagan posible, estos términos no son mutuamente excluyentes, sino al contrario necesariamente inclusivos. Entre los usos y efectos del papel, la pluma o el lápiz, y la imprenta, el cinematógrafo y el computador, no hay un golfo sino un pasaje. Y lo que este pasaje nos enseña es que las máquinas nos han hecho a nosotros tanto como nosotros hemos hecho a las máquinas (Littau 2006: 59).

Leyendo una serie de novelas clásicas en las cuales la lectura misma juega un papel importante (de Madame Bovary a Fahrenheit 451 y El Mundo Feliz) Littau concluye que la lectura le parece peligrosa a muchos críticos desde el siglo XVIII al XX "porque es consumida por el cuerpo antes de ser digerida por la mente, un peligro que se liga al consumo pasivo, es decir a la sobre-identificación y la consecuente pérdida del yo” (2006: 75). El temor viene del sorprendente descubrimiento de que "la lectura actúa sobre el cuerpo y luego es actuada como respuestas corporales” (2006:75).

Siguiendo a Jauss, Littau propone una recuperación de la tríada clásica delectare (deleitar) docere (instruir) y movere (mover) para esbozar una revisión de la historia de la literatura que sea capaz de rescatar los dos momentos constitutivos de toda experiencia estética: “Cómo entonces la literatura actúa sobre el lector (lo afecta) y cómo el objeto literario es activamente constituido como objeto en el acto de su contemplación” (2006: 100).

En dicha trayectoria histórica las tres funciones integradas e igualmente importantes de la tradición retórica (docere, delectare y movere) tienen destinos dispares en el desarrollo de la crítica literaria. En la definición kantiana de lo sublime como aquello que estando más allá del conocimiento no puede ser enseñado o comprendido, y en su reinterpretación romántica que, pasando de la sensibilidad de los lectores a la del autor, hace de dicha experiencia el inspirado núcleo de toda obra literaria (y por lo tanto de su crítica), se evidencia un desplazamiento de los muy impresionables lectores al genio creativo original (un desplazamiento facilitado por la emergencia de los derechos de autor (copyright) y la producción masiva de libros). Al llegar al siglo veinte este desplazamiento de la audiencia al autor se completa con un giro hacia la obra misma:

Lo que el giro del lector al autor parecería iniciar, de manera análoga al giro del hacer (movere) al ser, es una crítica que, grosso modo, se dedica más a cuestiones relacionadas con la naturaleza de lo literario que a preguntas sobre la utilidad de dicha literatura. Allí la literatura no cumple ciertos fines, sino que es ella misma dicho fin (Littau 2006: 92).

Si el placer estético es bien contemplación desinteresada o, en la versión neomarxista, una forma de negatividad que interrumpe la lógica del capital, entonces sus efectos se basan en una distancia crítica respecto a las emociones del sujeto y en una capacidad para percibir el significado de la estructura o el sentido de la forma. La obra de arte ha devenido así autotélica. En un mundo que sobreestimula los placeres fáciles en las masas, la poesía se transforma en una forma de restaurar un orden o un equilibrio en la psique del individuo: "Todo parece indicar que en el lapso de poco más de un siglo el afecto ha pasado de lo sublime a la falacia. En ese mismo lapso también la figura del autor, tan central para la teoría romántica, es desplazada de la investigación literaria, y es el texto en si mismo el que ahora ocupa el centro" (Littau 2006: 96). La útil reacción de Littau frente a las certezas del humanismo clásico (que nosotros controlamos completamente la tecnología, y que nos conocemos y controlamos a nosotros mismos en cuanto seres racionales) nos recuerda que: primero, "los objetos materiales determinan las prácticas de lectura” (los libros de bolsillo de comercialización masiva hicieron posible una cierta forma de novela y una cierta forma de consumo de dichas novelas); en segundo lugar, “ los lectores no son sólo hacedores de sentido sino que leen también en la búsqueda de sensaciones” (como el cine, este tipo de literatura, especialmente ciertos tipos de novela, estimulan una reacción corporal antes de producir una forma de reflexión); y, en tercer lugar, que "la tecnología reorganiza nuestras modalidades cognitivas y perceptuales" (2006: 58). Estas conclusiones son muy útiles si queremos interrogar productivamente el presente y el futuro de las formas de lectura bajo condiciones tecnológicas radicalmente alteradas. 
El excelente libro de Karin Littau, sin embargo, también nos permite identificar dos zonas que requieren mayor exploración si se trata de entender qué ha sido, es y podrá ser la lectura. Una de estas zonas deriva de la crítica a su revisión de la trayectoria de la crítica y la estética modernas. En su descripción, el afecto es gradualmente separado de los efectos y esto, es sin duda, parcialmente correcto. Sólo lo es parcialmente, sin embargo, puesto que uno de los aspectos claves de la historia de la lectura en la modernidad larga es aquel que liga la lectura a la nacionalización de la educación masiva. En esta historia alternativa de la lectura, allí donde consideramos no las lecturas y los lectores individuales sino sus contextos institucionales, el afecto y los efectos no sólo no están separados, sino que su conexión resulta fundamental para los esfuerzos de nacionalización pedagógica. Así por ejemplo, los chilenos devienen chilenos en la clase de Lengua en virtud de la capacidad de ésta de ligar sus vidas cotidianas y sus afectos con sus respectivas representaciones tanto en las composiciones escolares como en la literatura realista nacional que pronto les siguió. Dicha literatura nacional intenta precisamente mediar la distancia entre la literatura alta (conceptual, difícil pero moral e intelectualmente productivas) y la baja (popular, emotiva y profundamente sentida); mediar entre efectos cognitivos y morales por un lado y afectos físicos y fisiológicos, por otro. Conectar la mente y el cuerpo de todos los ciudadanos (Poblete 2003).

El segundo aspecto que Littau no desarrolla cabalmente es la conexión entre, por un lado, las tecnologías, los usos sociales y las formas de consumo que ellas permiten y propician y, por otro, la historia del capitalismo.

Aunque Littau señala correctamente que "Con cada invención de un nuevo medio — film, tecnologías digitales, o la novela - lo que preocupa a los críticos es la reinvención de la respuesta afectiva,” ella usa su argumento casi exclusivamente para criticar el prejuicio humanista contra el afecto, las sensaciones y los sentimientos. Con ese foco - $-\mathrm{y}$ aunque Littau reconoce el poder cambiante de las tecnologías para dirigirse a nuestros sentidos - no logra historizar la relación entre las tres tecnologías modernas que le interesan y el capitalismo como modo de producción de lo social. La relación entre el impacto de la tecnología y sus efectos sobre los usuarios está siempre presente en su argumento, pero es siempre, curiosamente, ahistórica. Lo que Littau no logra explorar es cómo, en la modernidad, no es sólo la invención misma de un nuevo medio sino la capacidad del capitalismo para expandir y explotar, para deslumbrar y capturar las respuestas afectivas a dichos medios, lo que hace la diferencia cualitativa. Y que este rol cambiante de dichas tecnologías en o dentro del funcionamiento del capitalismo, desde el capitalismo industrial al llamado capitalismo cognitivo, es también algo que debe ocupar al investigador o crítico actual.

Si ahora, con el beneficio de este resumen crítico de las ideas de Wolf y Littau, volvemos rápidamente a la segunda dimensión de las preguntas del comienzo —es decir, qué ha sido la lectura históricamente, cómo ha evolucionado, cómo ha sido usada, por quién y en qué contextos- es posible decir que la historia de la lectura literaria en la modernidad ha sido una larga trayectoria de formación de sujetos en la cual se han explotado tanto las capacidades intelectuales y cognitivas de la lectura en cuanto práctica, como las capacidades emotivas y afectivas que involucra. En dicha trayectoria, diferentes agentes en diferentes grados de colaboración y oposición —incluyendo el sujeto, el estado, las diferentes iglesias o credos, y todo tipo de configuraciones de mercadohan sido actores y espacios cruciales en el proceso de formar, o intentar formar, sujetos, intelectual y emocionalmente. Así, por ejemplo, además de las teorías de Benedict Anderson sobre el rol cultural de la lectura de novelas y periódicos en la construcción de la nación, se ha dicho que la novela realista y su lectura proporcionan soluciones imaginarias a las contradicciones reales del mundo social (Jameson, 1982; Sommer, 1990); que constituyen una forma de control social que produce subjetividades educadas por la alfabetización, el discurso y la lectura (Armstrong, 1991); que ambas le permiten a las burguesías nacionales una forma de autocomprensión (Watt 1957); y que ambas son parte de la construcción de "un sistema de significación cultural (...) a través de la representación de la vida social” (Bhabha 1991: 1-2). La lectura literaria, en cuanto incorporada al currículum escolar de la educación pública y obligatoria, ha tenido un papel clave en la producción de tales sujetos. Dicha producción, además, ha involucrado siempre lo intelectual y lo afectivo, o, para decirlo de una manera más tradicional, las mentes y los corazones de todos los ciudadanos. 
Para pasar ahora a la tercera pregunta, a la cuestión de qué sea la lectura hoy, hay que comenzar destacando que cualquier respuesta tendrá que reconocer que la lectura es una actividad que involucra tanto las funciones cognitivas como el cuerpo, tanto el pensamiento como la respuesta somática (incluyendo las sentimentales); que concierne tanto el discurso de lo literario cuanto los medios tecnológicos que lo han vehiculado; y que, por último, la historia de la literatura y de la lectura literaria proporcionan abundantes pruebas que confirman las complejas interrelaciones históricas entre estas dos áreas de un impacto siempre hecho posible por diferentes tecnologías de comunicación impresa. ¿Qué pasa, por ejemplo, con nuestros esfuerzos por entender el rol de la lectura hoy, si pensamos la lectura literaria en el contexto de un doble legado que incluye entre sus consecuencias, de maneras igualmente relevantes, la reacción afectiva y la pausa de reflexión? Una herencia que en vez de oponer la literatura a la distracción y a la sobre-estimulación, considera la lectura literaria como una forma de práctica inscrita en el campo más amplio de la atención y la estimulación sensorial en la modernidad. ¿Hay una forma específicamente literaria de la reacción afectiva o la atención corporal que podría o, incluso, debería ser rescatada junto con las formas preferidas de la concentración o atención cognitiva que tendemos a favorecer en nuestras defensas de lo literario y su lectura?

Nuevamente Maryanne Wolf viene en nuestra ayuda. En un artículo del 2009 ella insiste en la importancia de la "lectura profunda". Por lectura profunda Wolf entiende "[el] conjunto de sofisticados procesos que impulsan la comprensión e incluyen el razonamiento inferencial y deductivo, las capacidades analógicas, el análisis crítico, la reflexión y la iluminación.” (Wolf y Barzillai 2009: 32). Si el cerebro entrenado en este tipo de lectura ahorra cada vez cruciales fracciones de segundo que le permiten concentrarse en la verdadera producción de sentido, y si el cerebro no entrenado demora años de entrenamiento para llegar a ese punto, el nuevo énfasis de la cultura digital en "lo inmediato, la carga informativa y un set de habilidades cognitivas determinadas por los medios mismos que celebra la velocidad y desincentiva la reflexión tanto en nuestra lectura como en nuestro pensar” (Wolf y Barzillai 2009: 32) es, para Wolf, un alejamiento respecto a tal meta y, tal vez, incluso una amenaza a la posibilidad de su consecución. El acceso fácil a una cantidad abrumadora de información, la atención múltiple y la relativa distracción o cambios de atención que, si no necesarios, son con frecuencia estimulados por la lectura en línea, "pueden interrumpir el desarrollo de procesos de comprensión más lentos, con una demanda cognitiva mayor, involucrados en la formación de la lectura y el pensar profundos” (Wolf y Barzillai 2009: 35). La autora concluye recomendando tanto un nuevo entrenamiento en lectura profunda para prácticas en línea como un renovado esfuerzo por producir las habilidades de la lectura profunda a través de la más tradicional lectura de libros.

\section{Repensando la lectura.}

Aunque es fácil compartir la conclusión de Wolf, ella deja fuera el problema de qué hacer con la lectura en línea en sí misma o con las muchas formas de lectura que, no siendo académicas, no dependen de ese tipo de definición de la lectura profunda. ¿Deberíamos ignorarlas? ¿No podríamos usarlas en la clase?

Jim Collins, tanto en su libro Bring on the Books for Everybody: How Literary Culture Became Popular Culture (Traigan los libros para todos: Cómo la cultura literaria devino cultura popular) como en un artículo en la revista PMLA, propone la idea de un entorno mediático cambiante "determinado por la convergencia creciente de las culturas literaria, visual y material” (2010: 208) El resultado, que Collins celebra, es que “ la sinonimia [o relación necesaria] entre la lectura, el libro y la ficción literaria, está desarmándose” (2010: 207). Esto es importante por cuanto nos permite ir más allá de la oposición entre aquellos que defienden "la experiencia literaria tradicional” y lamentan su decadencia y aquellos que celebran la cultura digital. En este contexto la distinción "entre un sistema de acceso y un medio" es clave. Como ocurrió en el caso de la música grabada (el medio) y "los cilindros, discos, CDs y archivos de MP3" (sucesivos sistemas de acceso) Collins propone que "podría argumentarse que el cambio de lector de pulpa o celulosa a lector electrónico es un cambio en el sistema de acceso" (2010: 210) y que éste ocurre dentro del mismo medio (ya sea la literatura o la novela). Además, Collins propone separar los diferentes factores de la experiencia literaria ("un objeto llamado libro, un formato narrativo extenso, un grado de involucramiento llamado lectura atenta o profunda; y una cultura literaria que determina qué pertenece a cada 
categoría” (2010: 210) para ver cómo le va a cada uno de estos elementos en la cultura digital. Es posible que el libro sea totalmente reemplazado por los lectores electrónicos, pero la narrativa larga, por ejemplo, puede estar más sana y viva que nunca en las largas narrativas audiovisuales de los canales de TV por cable HBO o AMC. Dicho de otro modo, cuando uno separa dichos elementos, la desaparición del libro, por ejemplo, no implica una cultura de bits o trocitos y no significa la desaparición de la forma narrativa larga. Del mismo modo, "la lectura como auto-transformación del sujeto" no depende del libro y podría, en rigor, resultar fortalecida por las formas de personalización o curadoría individual o 'playlisting' de nuestros archivos que, en la cultura digital, mezclan “socialización e intimidad”, ofreciendo al lector 'los placeres tanto de la hiper-socialización como los de la hiperpersonalización” (2010: 211).

Katherine Hayles, por su parte, piensa que tanto las prácticas de lectura en línea como las no-literarias pueden y deben ser usadas y aprovechadas en la escuela. En un artículo titulado "La hiperatención y la atención profunda: La división generacional de los modos cognitivos” Hayles explica por qué.

De acuerdo a la hipótesis de Hayles "estamos en pleno proceso de un cambio generacional de estilos cognitivos que presenta desafíos a la educación en todos los niveles” (2007: 187). Nos movemos, según Hayles, de una cultura que ha cultivado y valorado la atención profunda a otra que produce y promueve la hiper-atención. Este cambio generacional trae consigo que los jóvenes prefieran, o incluso requieran, mayores niveles de estimulación en su consumo cultural, acercándose a lo que la cultura tradicional habría descrito como AD/HD (attention déficit hyperactivity disorder o trastorno por déficit de atención e hiperactividad). “AD/HD podría ser mejor descrito como 'la búsqueda del desorden de estimulación” (2007: 190). En vez de lamentar este desarrollo, Hayles piensa que a) la hiperatención puede ser más apropiada para una serie de tareas en la vida contemporánea; y b) que los medios digitales y la estimulación que ellos producen "podría contribuir a una combinación sinergética de atención profunda e hiper atención” (2007:193) si se las estructura de la manera adecuada. En este contexto, una estructuración adecuada en un video juego educacional, por ejemplo, puede involucrar altos niveles de interactividad y una forma de estimulación o involucramiento "asociado con sentimientos de autonomía, competencia, y relación” (2007: 195).

La cuidadosa propuesta de Hayles en el campo minado de los estudios sobre la atención, contrasta con dos formas opuestas de populismo sobre el tema. Primero el de Cathy Davidson en su libro Now You See it. How the Brain Science of Attention Will Transform the Way we Live, Work and Learn (2011). Allí la autora declara: "La época en que vivimos presenta desafíos únicos a nuestra atención. Exige una nueva forma de atención y un nuevo estilo de concentración (focus) que requieren, a su vez, tanto un nuevo acercamiento al aprendizaje como un rediseño de la sala de clase y el lugar de trabajo" (2011: 10). Este desafío, de acuerdo a Davidson, será superado cuando nos deshagamos de las formas de atención sostenida, repetitiva y concentrada en una sola tarea que privilegiaron el capitalismo industrial y la forma de escuela que éste generó, y las reemplacemos con dos nuevas formas de atención. Primero, una atención basada en la capacidad de des-aprender o refrescar nuestro software mental generando un ciclo de aprendizaje/des-aprendizaje/re-aprendizaje que, a su vez, "exige una distracción cultivada, porque, tan pronto como nos concentramos en el objeto que conocemos, perdemos de vista el nuevo que debemos ver” (2011: 19). En segundo lugar, y para no perder de vista este objeto nuevo, debemos implementar formas de colaboración en el trabajo o “colaboración por diferencia” (2011:19).

Enfrentamos una segunda forma de populismo en dos libros muy diferentes que, sin embargo, sostienen entre sí tesis muy similares: Distracted: The Erosion of Attention and the Coming Dark Age de Maggie Jackson (2009) y The Big Disconnect. The Story of Technology and Loneliness de Giles Slade (2012). Para Jackson:

En la medida en que nuestras habilidades atencionales son dilapidadas, nos hundimos en una cultura de desconfianza, superficialidad y una deshumanización que funde a la persona con la máquina. Mientras más cultivamos vidas de distracción más perdemos nuestra capacidad para crear y preservar sabiduría y más nos movemos hacia una época de ignorancia que surge, paradójicamente, en el medio de una gran abundancia de información y conectividad (2009: 16). 
Para Slade, por otro lado, el problema es que las máquinas están reemplazando las interacciones entre seres humanos. En la medida en que esas máquinas se tornan cada vez más eficaces en esta tarea, es posible que perdamos de vista lo que habremos perdido en el proceso. Las nuevas tecnologías y los medios sociales (social media) han exacerbado una tendencia de la vida urbana ya percibida por Georg Simmel a comienzos del siglo XX: la eliminación de las interacciones sociales debido a la velocidad, la eficiencia, el costo o el estrés.

Más interesantes que las teorías unilaterales que se concentran en un solo mecanismo de causa y efecto, me parecen los textos que interrogan las fronteras dentro de lo que podríamos llamar el espectro de prácticas formales e informales que afectan la cultura y la lectura en sus formas reales de existencia.

El libro de Mark Bauerlein The Dumbest Generation tiene un subtítulo que me ayuda en el trabajo de resumir su obra: How the Digital Age Stupefies Young Americans and Jeopardizes our Future (2008). En un prefacio a la versión de bolsillo de su libro, Bauerlein señala que, al formular su pregunta central sobre si el aumento del tiempo de pantalla idiotiza a nuestros hijos, su objetivo era "abrir el tema a un sobrio escepticismo capaz de contrastar el fervor tecnológico que se esparce por nuestras bibliotecas y salas de clase” (2009). La preocupación de fondo de Bauerlein es aún más interesante: la ilimitada vida en los medios sociales de nuestro adolescentes y la fuerte presión para participar, el contexto tecnológico digital permanente producido por esos mismos jóvenes que rodea tanto a niños como a adultos jóvenes, los están volviendo impermeables a la influencia de los adultos, la lectura y el conocimiento formal. En este caso el problema no es la desaparición de una práctica sino el balance o peso relativo entre prácticas culturales formales e informales.

De manera análoga, el libro 24/7, Late Capitalism and the Ends of Sleep de Jonathan Crary (2013) describe la configuración sociocultural contemporánea dentro del capitalismo como un entorno 24/7 (24 horas al día y siete días a la semana). En dicha situación "el modelamiento de la identidad personal y social ha sido reorganizado para que concuerde con la operación ininterrumpida de los mercados, la información, las redes y otros sistemas” (2013: 9). En este contexto el sueño (sleep, es decir, el dormir) es un remanente, una resistencia: "El sueño es una interrupción sin compromisos del robo del tiempo que perpetra en nosotros el capitalismo [...] presenta la idea de una necesidad humana y de un intervalo de tiempo que no puede ser colonizado ni aprovechado por una máquina gigantesca de generar ganancias” (2013: 10). La tesis central de Crary es que el sueño es un representante o sustituto de la verdadera "durabilidad de lo social": "En tanto es lo más privado, el estado de mayor vulnerabilidad que nos es común a todos, el sueño depende de una manera radical de la sociedad” (2013: 25). El sueño, como lo social, depende de la reciprocidad, la vulnerabilidad y la confianza. Es, también, el otro lado del biopoder atencional, un límite a la paradójica incapacitación de la experiencia visual en un contexto saturado por formas de audio-visualidad. Para Crary, esta dinámica "24/7 incapacita la [verdadera] visión a través de procesos de homogenización, redundancia y aceleración” (2013: 33).

Jonathan Beller, trabajando en un marco que combina marxismo y psicoanálisis con teorías sobre el trabajo afectivo bajo el nuevo régimen de producción capitalista, basado en la cultura y el conocimiento, ha propuesto en su libro The Cinematic Mode of Production: Attention Economy and the Society of the Spectacle (2006) el concepto del "modo de producción cinemático" para referirse a un nuevo modo de producción y dominación caracterizado por su dependencia del trabajo de los espectadores que producen el valor a través de su consumo de imágenes:

El concepto del modo de producción cinemático (CMP) sugiere que el cine y sus posteriores aunque coexistentes formaciones, especialmente la televisión , el video, los computadores y la internet, son fábricas desterritorializadas en las cuales laboran los espectadores produciendo un trabajo que genera valor” (Beller 2006: 61).

Bajo este régimen que fusiona "lo cultural, industrial, económico y psicológico", penetra el sensorium humano y lleva "la revolución industrial al ojo" al hiperdesarrollar el fetichismo de la mercancía, la imagen se transforma en un sinónimo de nuevas relaciones de producción que aseguran "la transferencia (es decir, la conversión en valor y 
en plusvalía) del biopoder atencional al capital” (2006: 61). De esta forma, el capitalismo, a través de su aparato mediático capitaliza "las facultades estéticas y las prácticas imaginarias de los espectadores" (2006:67) al hiperdesarrollar los componentes fetichísticos (visuales y libidinales) de las mercancías. En tanto mercancía hiperfetichizada, la imagen deviene el nombre y el medio a través del cual se produce esta radical "incorporación de la anteriormente semi-autónoma esfera de la cultura al capital” (2006:77) y el devenir material de las formas simbólicas.

Confirmando las hipótesis de Beller y Crary, pero desde el lado ideológicamente opuesto, el libro de Nir Eyal Hooked (2014) es, como indica su subtítulo How to Build Habit-Forming Products, directamente un manual sobre cómo captar y capitalizar el biopoder atencional. Para ello incluye capítulos como "La Zona de los hábitos”, "El Disparador”, "Recompensas variables”, "Inversión” y "La Medición de los hábitos y dónde buscar oportunidades de crear hábitos” (2014: índice, sin número de página).

$\mathrm{Si}$ — como ha dicho Fredric Jameson, el imperativo de mirar imágenes es central para el funcionamiento de la mayoría de las instituciones hegemónicas contemporáneas (citado por Crary, (2013:47)) o, como ha propuesto Crary, el aspecto más crucial de nuestro contexto $24 / 7$ es "cómo los ritmos, velocidades y formatos del acelerado e intensificado consumo están dando nuevas formas a nuestra experiencia y percepción” (2013: 39) — entonces las preguntas que más nos importan en el contexto de este ensayo son: ¿qué tipo de intervención sobre los modos dominantes de atención que definen el postmodernismo neoliberal y la cultura global podría ser la lectura? ¿De qué manera podría ella ayudarnos en la exploración de economías y regímenes alternativos de lo visible y lo legible, por un lado, y de lo social, por el otro?

Para entender la importancia y el potencial de la lectura literaria en la época de su desplazamiento por un contexto audiovisual 24/7 y por una forma de capitalismo basada en la explotación del biopoder atencional, podría resultar útil postular una hipótesis histórica que conciba la lectura literaria dentro de un espectro de prácticas formales e informales de concentración de la atención, en el doble sentido de enfoque y explotación de dicha atención.

Lo que es preciso entender, entonces, es que el contexto dentro del cual estas prácticas formales e informales de atención se desarrollan, ha cambiado y con este cambio podría estarse generando una redefinición paradojal de la relativa centralidad e importancia de la lectura literaria. Para mayor claridad, voy a reformular la naturaleza de dicho cambio: el contexto de la lectura literaria, que fue alguna vez una tecnología clave para la producción de individuos burgueses y socialistas y sus subjetividades, es ahora el del neoliberalismo, la internet y los nuevos medios. Estos últimos se basan en la expansión de formas de privatización y mercantilización de la experiencia y la atención. La literatura fue alguna vez, por un lado, una manera de producir sujetos nacionalizados y de educar a las clases medias, creando subjetividades individuales para el goce pleno de su hegemonía sociopolítica, y, por otro, una forma de educar al proletariado en la defensa colectiva y la realización de sus supuestos intereses de clase. Hoy, en cambio, la individualización de la oferta cultural y las formas administradas y mercantilizadas de aprovechar la atención y las energías biopolíticas, la invitación al prosumidor de participar en la producción de un capitalismo basado en incorporación cabal de los afectos, la socialidad y la vida individual al ámbito de lo completamente explotable, han cambiado el contexto de ocurrencia de lo literario como práctica social. Han cambiado también el continuo de prácticas formales e informales a las que pertenece y, por ende, su valor cultural y político.

La expansión de la capacidad del capitalismo de mercantilizar y codificar para su explotación sectores cada vez más amplios de la vida - lo que a veces se denomina el fin de la transcendencia y la inmanencia cabal del capitalismo en la vida — han resultado en una condición radicalmente alterada para la práctica literaria.

En primer lugar, la historia de la lectura en Occidente, como hemos visto, combinó procesos completamente institucionalizados, que usaron la lectura intensiva en la escolarización para construir sujetos nacionalizados, con otros menos formales o menos estructurados que participaron de una economía informal del placer en lecturas extensivas que, supuestamente, redondearon los márgenes del sujeto estéticamente constituido. Ahora, en cambio, 
las proporciones se han invertido. La economía formal, la educación y, especialmente, la educación literaria nacionalista parecen menos relevantes para la producción de sujetos productivos que el lado informal, de participación voluntaria en medios sociales llenos de lectura y escritura. Esta última ha devenido la forma dominante de incorporar sujetos productivos a las nuevas economías de la atención y la captura y explotación del afecto.

En segundo lugar, el status histórico especial de la lectura como práctica material y psicológica radicalmente diferente de lo que la mayoría de la población hacía durante el día, su naturaleza de quiebre con lo cotidiano que le permitía una atención sostenida a lo cotidiano, han sido suplantados en la lectura electrónica por una forma de continuidad entre dicha lectura, las plataformas de lectura y las actividades que la mayoría de nosotros realiza con mayor frecuencia, es decir, interactuar de maneras productivizables con aparatos electrónicos que miden captan y mercantilizan nuestra atención o la de nuestros ojos. La lectura fue alguna vez como el sueño, relativamente nomonetizable (de hecho, con frecuencia se la describió como lo contrario del tiempo productivo). Hoy en cambio, es parte integral de la nueva economía de la atención 24/7. Estas dos observaciones abren la posibilidad de especular acerca de la importancia actual y futura de la lectura literaria en nuestra cultura.

\section{Conclusión}

A la luz de las ideas de Wolf sobre el cerebro lector y lo que este aporta a la cognición, las de Littau sobre la historia de nuestro involucramiento corporal con lo literario, y las de Crary y Beller sobre la captación del biopoder atencional, resulta interesante pensar en la famosa hipótesis de Viktor Shklovsky sobre lo que define al arte. Si el arte es lo que nos permite desfamiliarizar las cosas, para hacer posible la percepción de un objeto como si este fuera visto y no re-conocido, es decir, una experiencia del objeto por primera vez y no ya filtrado por nuestros esquemas perceptivos que, al disminuir el tiempo de procesamiento de lo real, permiten el reconocimiento cognitivo a través de una simplificación de la verdadera complejidad de los datos, entonces el arte y la lectura de lo literario como arte son, en un cierto sentido, un movimiento contrario a este último, un movimiento en la dirección opuesta a aquella del economizar los medios, la energía y el tiempo que es lo que define al cerebro lector. Este contra-movimiento supone no sólo el nuevo gasto de energía en cuanto reflexión intelectual concentrada, sino también toda la energía afectiva que una buena lectura puede involucrar.

Esta contradicción, esta economía de la energía cerebral hecha posible por el reconocimiento de patrones que a su vez posibilitan un gasto ulterior de dicha energía en la reflexión cuidadosa o la experiencia afectiva de las singularidades percibidas como tales (es decir no acortadas por los esquemas conceptuales o incluso contra dichos esquemas) es la tensión constitutiva y definidora de la lectura literaria. Nos movemos neurológicamente más rápido en virtud de los circuitos cerebrales integrados de reconocimiento de patrones que la lectura misma ha creado, para pasar más y más tiempo reflexionando sobre o sumergiéndonos afectivamente en lo que leemos, transformando así la actividad en una experiencia personal y cultural de profundo significado.

A esta contradicción constitutiva de la lectura literaria se añade ahora el hecho que las prácticas de atención profunda que ella promovió, tanto al nivel formal como informal, se hallan hoy completamente rodeadas por prácticas afectivas y efectivas, cada vez más abarcadoras, formales e informales, de hiperlectura, cambio de labores (task switching) y atención dispersa.

Hay por lo menos dos conclusiones que se derivan de esta revisión de las preguntas qué es, qué ha sido y qué podría ser la lectura. Primero, que la ecología cultural, dentro de la cual acontece la lectura literaria o de otro tipo, ha cambiado significativamente como resultado de las nuevas tecnologías y medios. Este cambio ha ocurrido tanto al nivel del consumo — donde la lectura está cada vez más conectada a pantallas y está constantemente disputándose la atención del consumidor con otros medios, otros discursos y las formas de consumo que ellos estimulan — como al nivel de la producción, donde la escritura ya no está restringida a los creadores profesionales y los espacios institucionales.

Segundo, que esta nueva ecología mediática dentro de la cual la lectura literaria tiene lugar ha desafiado las 
formas de legitimación moderna de lo literario y sus prácticas de lectura, entendidas como capital cultural de las burguesías nacionales o deliberada auto-formación intelectual individual.

Desprovista de esta forma de legitimación, o al menos cuando ella ha sido desafiada, la práctica pedagógica basada en la literatura ya no puede tampoco auto-justificarse exclusivamente por la vía de apelar a lo estético (en el sentido kantiano), como su terreno privilegiado, y a las formas de conocimiento no-utilitarias, como su característica principal. Tampoco puede, final e inversamente, autodefinirse reclamando ser la única o la principal fuente de alfabetización cultural efectiva y necesaria para un sujeto educado contemporáneo. La literatura y la lectura literaria han sido pluralizadas desde adentro y desde afuera, desde abajo y desde arriba.

En el cambio latinoamericano de siglo, del XIX al XX, para no dar sino un ejemplo histórico, el latín como materia escolar había sido obligado a autodefinirse como la única materia escolar capaz de proporcionar a la élite educada una forma de gimnasia mental intelectualmente productiva y una formación ética del sujeto que se asociaban directamente con su dificultad. Muy pronto ese latín escolar fue descartado y reemplazado por una materia más moderna y funcional que reclamaba para si, no la dificultad sino, en cambio, ser la única práctica pedagógica capaz de producir las formas de subjetividad y ciudadanía nacionales requeridas por el estado-nación moderno (Poblete 2003 y 2004b).

La lectura literaria debe, y tal vez tiene que, aprender de esta historia. No puede simplemente atrincherarse detrás de narrativas de auto-justificación basadas en aquella gimnasia de la dificultad o en otras fundadas en el reclamo puramente instrumental de la efectividad. En cambio debe celebrar y aceptar, aquilatando y explotando cabalmente cada una de ellas, la multiplicidad de prácticas formales e informales de un estudiantado además, altamente diversificado, a través de las cuales diversos textos devienen ocasiones propicias para la reflexión y la experiencia. Esta dinámica ha sido siempre parte importante de la historia de la lectura en Occidente.

La literatura, y con ella la lectura literaria, deben aceptar su lugar en este espectro de prácticas y usarlo para estructurar su propio quehacer. Al postular una interacción constante entre los lados formales e informales de la ecología de la lectura, sería posible pensar, y ello ya ha parcialmente ocurrido en muchas de nuestras aulas, que los estudios literarios y sus formas privilegiadas de lectura tienen como objeto, precisamente, esa interdependencia de las dos economías y formas de la lectura. Si el aula universitaria ha sido siempre una zona de contacto en que se encuentran las culturas de lectura que nuestros estudiantes traen desde sus vidas cotidianas y la escuela secundaria con los protocolos de lectura profunda que intentamos enseñarles, el desafío hoy sería cómo profundizar esa visión de la interdependencia de las dos economías y hacerla una parte clave de nuestra práctica teórica y pedagógica.

Todo ello trae consigo algunas conclusiones claves.

Es necesario que la literatura y lectura literaria sean capaces de complementar e interactuar con otros medios y sus formas de alfabetización o competencia, en vez de simplemente denunciar apocalípticamente su llegada; en segundo lugar, es preciso reclamar la lectura en todas sus variedades (no sólo la lectura detenida o close reading formalista o el estudio sociológico o cultural, sino también lo ético y lo práctico) como partes cruciales de una cadena que, basada en la lectura, incluye, primero, la capacidad de pensar, hablar y escribir críticamente sobre cualquier tema académico, incluyendo la literatura; y segundo, la capacidad de sumergirse en otros mundos y considerar la perspectiva de los otros, ficcionales y no ficcionales. Podría significar también colocar a la lectura, es decir, la forma de atención a la escritura y a la forma misma de lo escrito que la lectura involucra, en el centro de una nueva ecología y economía de la atención y la información. En vez de lamentar el supuesto fin de la lectura literaria podríamos reclamarla, ahora expandida y diversificada, como una forma particularmente efectiva y empoderante de práctica de atención a la atención, en toda su verdadera complejidad. Esto significaría proponerla como una práctica que es necesaria por sus propios y múltiples fines, y que es, también, clave para otras formas de alfabetización mediática, siempre y cuando entendamos que esa atención a la atención supone tanto la capacidad de impacto intelectual y cognitivo como la capacidad de afectar el cuerpo y las emociones de los sujetos 
involucrados, a través de una estimulación compleja. Una práctica que en su propia tensión constitutiva entre resultados corpóreos e incorpóreos, efectos cognitivo-intelectuales y emocionales, pueda enseñarnos lo que necesitamos saber sobre el funcionamiento básico del nuevo cocktail para la formación de sujetos que el capitalismo de la información, la cognición y la hiper-estimulación nos tiene preparado. Una práctica, entonces, absolutamente esencial para vivir, aprender, pensar y sentir mejor en el presente y, especialmente, en el futuro.

\section{BIBLIOGRAFÍA}

Armstrong, Nancy (1987). Desire And Domestic Fiction: A Political History Of The Novel, New York, Oxford University Press.

Beller, Jonathan (2006). The Cinematic Mode of Production: Attention Economy and the Society of the Spectacle, Dartmouth, University of New England Press.

Bauerlein, Mark (2008). The Dumbest Generation: How the Digital Age Stupefies Young Americans and Jeopardizes our Future, New York, Tarcher/Penguin.

Bauerlein, Mark. (2009). Is technology turning our kids into "The Dumbest Generation? National Review, 14 de mayo. Recuperado de http://www.nationalreview.com/article/227469/cultural-illiteracy-mark-bauerlein

Bhabha, Homi K. (1991). Introduction. En Homi K. Bhabha (editor). Nation and Narration. (pp.1-7). London, Routledge.

Collins, Jim (2010). Bring on the Books for Everybody: How Literary Culture Became Popular Culture, Durham, Duke University Press.

Collins, Jim (2013). Reading in a Digital Archive of One’s Own, PMLA 128.1, pp.207-212.

Crary, Jonathan 2013). 24/7, Late Capitalism and the Ends of Sleep, Londres: Verso.

Davidson, Cathy (2011). Now You See it. How the Brain Science of Attention Will Transform the Way we Live, Work and Learn, New York, Penguin.

Eyal, Nir (2014). Hooked. How to Build Habit-Forming Products, New York, Portfolio-Penguin.

Hayles, Katherine (2007). Hyper and Deep Attention: The Generational Divide in Cognitive Modes, Profession, pp.187-199.

Jackson, Maggie (2009). Distracted: The Erosion of Attention and the Coming Dark Age, New York, Prometheus Books.

Jameson, Fredric (1982). The Political Unconscious. Narrative as a Socially Symbolic Act, Ithaca, Cornell University Press.

Littau, Karin (2006) Theories of Reading: Books, Bodies, and Bibliomania, Cambridge: Polity. (Teorías de la lectura, Buenos Aires, Manantial, 2014.)

Poblete, Juan (2003) Literatura chilena del siglo XIX: entre públicos lectores y figuras autoriales, Santiago, Editorial Cuarto Propio.

Poblete, Juan (2004a). Reading as a Historical Practice in Latin America: the First Colonial Period and the Nineteenth Century. En Mario J. Valdés and Djelal Kadir (editores), Latin American Literary Cultures: A Comparative History of Cultural Formations, (pp.178-192). Oxford University Press, Vol. I. (Disponible ahora en español: "De la lectura como práctica histórica en América Latina: la primera época colonial y el siglo XIX", 
en Cuadernos de Literatura, Universidad Javeriana (Bogotá, Colombia), XX, 39, Enero-Junio, 2016, pp.57-94.)

Poblete, Juan (2004b). Literary Education and the Making of State Knowledge, en Mario J. Valdés and Djelal Kadir (editors), Latin American Literary Cultures: A Comparative History of Cultural Formations, (pp.300-309). Oxford University Press, Vol. III.

Shklovsky, Viktor (1990). Theory of Prose, Champaign, Dalkey Archive Press.

Slade, Giles (2012). The Big Disconnect. The Story of Technology and Loneliness, New York: Prometheus Books. Sommer, Doris (1990). Irresistible Romance: the Foundational Fictions of Latin America. En Homi K. Bhabha (editor). Nation and Narration, London, Routledge, pp.71-98.

Watt, Ian (1957). The Rise of the Novel: Studies in Defoe, Richardson and Fielding, Berkeley, University of California Press.

Wolf, Maryanne (2007). Proust and the Squid. The Story and Science of the Reading Brain. (Cómo aprendemos a leer, Barcelona, Ediciones B, 2008.)

Wolf, Maryanne and Barzillai, Mirit (2009). The Importance of Deep Reading, Educational Leadership, 66:6, pp.32-37. 